\title{
Evolution of the human fear-circuitry and acute sociogenic pseudoneurological symptoms: The Neolithic balanced-polymorphism hypothesis
}

\author{
H. Stefan Bracha*, Dawn T. Yoshioka, \\ Nicole K. Masukawa, Deborah J.J. Stockman \\ National Center for Posttraumatic Stress Disorder Department of Veterans Affairs, \\ Pacific Islands Health Care System Spark M. Matsunaga Medical Center 1132 Bishop St. \#307, Honolulu, USA
}

Received 10 December 2004; accepted 16 May 2005

Available online 18 August 2005

\begin{abstract}
In light of the increasing threat of large-scale massacres such as terrorism against non-combatants (civilians), more attention is warranted not only to posttraumatic stress disorder (PTSD) but also to acute sociogenic pseudoneurological ("conversion") symptoms, especially epidemic sociogenic symptoms. We posit that conversion disorders are etiologically related to specific evolutionary pressures (inescapable threats to life) in the late stage of the human environment of evolutionary adaptedness (EEA). Bracha et al. have recently argued that from the neuroevolutionary perspective, medically unexplained efferent vasovagal syncope and medically unexplained craniofacial musculoskeletal pain in young otherwise healthy individuals, may be taxonomized as stress and fear-circuitry disorders. In the present article, we extend neuroevolutionary perspectives to acute pseudoneurological sociogenic ("conversive") symptoms: psychogenic non-epileptic attacks ("pseudoseizures"), epidemic sociogenic disorders (DSM-IV-TR Epidemic "Hysteria"), conversive motor deficits (pseudo-paralysis and pseudocerebellar symptoms), and psychogenic blindness. We hypothesize that these perplexing pseudoneurological stress-triggered symptoms, which constitute psychopathology in extant humans, are traceable to allele-variant polymorphisms which spread during the Neolithic EEA. During Neolithic warfare, conversive symptoms may have increased the survival odds for some noncombatants by visually (i.e., "non-verbally") signaling to predatory conspecifics that one does not present a danger. This is consistent with the age and sex pattern of conversive disorders. Testable and falsifiable predictions are presented; e.g., at the genome-transcriptome interface, one of the major oligogenic loci involved in conversive spectrum disorders may carry a developmentally sensitive allele in a stable polymorphism (balanced polymorphism) in which the gene expression mechanism is gradually suppressed by pleiotropic androgens especially dehydroxyepiandrosterone sulfate (DHEA-S). Taxonomic implica-
\end{abstract}

\footnotetext{
* Corresponding author. National Center for PTSD, Department of Veterans Affairs, Pacific Islands Health Care System, Spark M. Matsunaga Medical Center, 1132 Bishop St., Ste. \#307, Honolulu, HI 96813-2830, USA. Tel.: +1 808566 1652; fax: +1 8085661885.

E-mail address: h.bracha@med.va.gov (H.S. Bracha).
} 
tions for the much-needed rapprochement between the forthcoming Diagnostic and Statistical Manual for Mental Disorders, Fifth Edition (DSM-V) and the International Classification of Diseases (ICD) are discussed.

Published by Elsevier B.V.

Keywords: Allele-variant polymorphisms; Conversion disorder; DSM-V; Terrorism; Combat; War

\section{Contents}

1. Distal (evolutionary) etiological perspectives in psychiatry . . . . . . . . . . . . . . . . . . . . 120

2. Up to $95.3 \%$ of conversive symptoms remain unexplained . . . . . . . . . . . . . . . . . . . . 121

3. Pseudoneurological symptoms as fitness-enhancing Neolithic fear responses . . . . . . . . . . . . . . . . . 122

4. Neolithic inter-tribal warfare patterns and pseudoneurological conversive symptoms . . . . . . . . . . . . . 122

5. Subtypes within the sociogenic-conversive spectrum . . . . . . . . . . . . . . . . . 123

5.1. Acute fear-induced motor deficits . . . . . . . . . . . . . . . . . . . . . . 123

5.2. Sociogenic fear-induced motor (non-epileptic) attacks . . . . . . . . . . . . . . . . . . . . 123

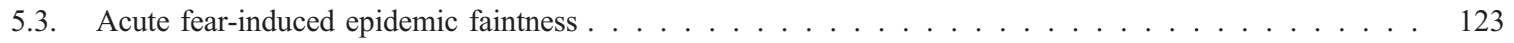

6. Insights from recent bio-anthropological research . . . . . . . . . . . . . . . . . . . . . . . . . . . . 124

7. Implications for DSM-V and some empirically testable and falsifiable predictions . . . . . . . . . . . . . . . 124

7.1. Predictions for research across culture-bound genomes . . . . . . . . . . . . . . . . . . . . 124

7.2. Toward a rapprochement between DSM and the European ICD . . . . . . . . . . . . . . . . . 125

7.3. Conversive (pseudoneurological) disorder may be a more robust construct than dissociation,
and thus a better target for biological research . . . . . . . . . . . . . . . . . . . 125

7.4. Implications for the taxonomy of fear-induced faintness in DSM-V . . . . . . . . . . . . . . . 125

7.5. Some possible implications for the DSM-V terminology . . . . . . . . . . . . . . . . . 125

7.6. Predictions empirically testable in non-human simians. . . . . . . . . . . . . . . . . . . . 126

7.7. Predictions for transcriptomic research into the sociogenic (conversive) spectrum. . . . . . . . . . 126

7.8. Testable pharmacological treatment approaches . . . . . . . . . . . . . . . . . . 126

7.9. Toward stigma reduction in clinical settings . . . . . . . . . . . . . . . . . . . . . . . . . . . . . . . . . . . . . . .

7.10. Toward a psychiatric taxonomy that is more etiologically based. . . . . . . . . . . . . . 126

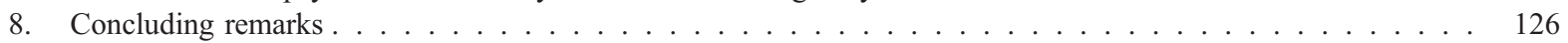

9. In summary . . . . . . . . . . . . . . . . . . . . . . . . . . . . . 127

Acknowledgements . . . . . . . . . . . . . . . . . . . . . . . . 127

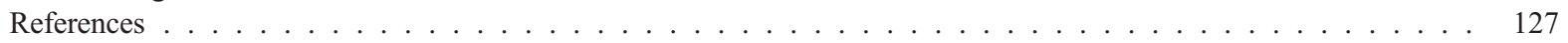

\section{Distal (evolutionary) etiological perspectives in psychiatry}

This article's focus on the question of "why" (distal or neuroevolutionary etiology) may be a useful complement to the standard biological psychiatric research focus on "how" (proximal/proximate or neurochemical etiology). Experimental and evolutionary neuroscientists have cogently argued that the distal/ultimate etiology of many phobias is a fear-circuitry adaptation that served to enhance survival and reproduction during mammalian or early primate evolution. For landmark empirical studies and comprehensive recent reviews of the empirical research, see Cosmides and Tooby (1992, 1999), Blanchard et al. (1993), Cook and Mineka (1989, 1990), Menzies and Clarke (1993), Ohman and Mineka (2001) and Poulton et al. (1999).

The neuroevolutionary perspective is most clear regarding specific phobias triggered by situations that were potentially lethal throughout the human EEA, such as high elevations, confined spaces, or being under the simultaneous visual scrutiny of many non-kin conspecifics. Nesse summarized most of the literature prior to 1999 in a series of landmark reviews (Nesse, 1999a,b). Nesse has pointed out that 
subsequent assortative mating may also play a role in amplifying polygenic transmission resulting in shifting the severity of these responses from the normative range into the clinical range (a similar argument can be made for oligogenic transmission). Similar perspectives were echoed by Bracha (in press, 2004), Bracha et al. (2005a), Buss et al. (1998), Marks (1987, 1988), Klein (1993), Marks and Nesse (1997), Niculescu and Akiskal (2001), Perry and Pollard (1998), Perry et al. (1995), and Stein and Bouwer (1997).

More recently, we have argued that from a neuroevolutionary (distal etiology) perspective, medically unexplained facial pain, clenching-grinding symptoms, as well as habitual efferent vasovagal neurocardiovascular syncope, are traceable to fear-circuits wired during the early Paleolithic (early Pleistocene) or earlier, and conserved in the human clade, and may be taxonomizable in the fear-circuitry disorders spectrum (Bracha, 2004; Bracha et al., 2005a,b).

In light of the increasing threat of large-scale massacres, especially terrorist attacks against non-combatants (civilians), more attention to sociogenic symptoms, particularly epidemic sociogenic symptoms, may be warranted (Bartholomew and Wessely, 2002; Wessely, 2000). Biological psychiatric researchers have paid little attention to this perplexing spectrum of fearinduced syndromes. While the evolutionary etiology of many specific phobias is intuitively clear, certain symptoms within the sociogenic-conversive spectrum remain less obvious.

In a landmark article on dissociative symptoms, Perry et al. have pointed out that:

"Humans evolved... in the presence of two major predators: large cats (e.g., tigers, panthers) and, the most dangerous predators, other hominids, including humans... To the cats, all humans (males, females, and children) were roughly equivalent prey, with some preferences for the small, slow, and weak. To other hominids, however, there was a dramatic difference between males, females, and young children... One need not imagine long the response of a violent human male when faced with one female who will willingly comply with the commands to move to his camp and with another who is screaming, yelling, hitting, fighting, and trying to run away. Hyperarousal (fighting or fleeing) would clearly reduce... the prob- ability that her genes would be passed to another generation" (Perry et al., 1995).

In the present article, we extend a similar neuroevolutionary perspective to acute pseudoneurological symptoms. This neuroevolutionary hypothesis is complementary to the clinical and basic research on the neurophysiology (proximal/proximate etiology) of conversive spectrum disorders. Our primary focus is on psychogenic, non-epileptic attacks ("pseudoseizures"), and epidemic sociogenic syndromes (epidemic faintness being the most common form) (Boss, 1997; Moffatt, 1982; Van Ommeren et al., 2001).

Some pseudoneurological symptoms, which have outlived their usefulness and thus are non-fitnessenhancing in the modern environment, may have been fitness-enhancing fear-circuitry responses to war-related, inescapable stress in the late stage of the human EEA. We posit that a firm-wired (prepotentiated) limbic extreme-stress response resembling a severe handicap, such as pseudo-paralysis (limping), pseudo-cerebellar symptoms (staggering), psychogenic loss of eyesight (psychogenic blindness), or psychogenic motor attacks (falling to the ground with epileptic-like behavior) may have been selected into some genomes specifically during the Neolithic. We posit that during Neolithic periods of warfare, acute pseudoneurological symptoms may have provided a clear non-verbal (visual) signal to predatory conspecifics (often raiders from a tribe that spoke a different language) (Keeley, 1996; LeBlanc and Register, 2003) that one is severely injured or severely diseased and thus unlikely to be an immediate threat. Evolutionary pressures such as these have been shown to result in balanced (stable) polymorphisms (CavalliSforza, 2000; Cavalli-Sforza et al., 1994).

\section{Up to $95.3 \%$ of conversive symptoms remain unexplained}

In clinical settings, the importance of a comprehensive neuropsychiatric work-up of the first episode of acute conversive symptoms cannot be overemphasized (Saygi et al., 1992). However, the wording regarding conversive symptoms in the DSM-IV-TR reflects the extreme caution with which academic psychiatry presently regards these symptoms. This caution was lar- 
gely in response to the often cited 1965 study by Elliot Slater (Slater, 1965; Slater and Glithero, 1965). Slater found previously undetected localized neurological disorders in $56 \%$ of patients originally diagnosed with conversive disorders. However, newer, more carefully conducted studies do not support Slater's conclusions published 40 years ago. The 1998 study by Crimlisk et al. ("Slater Revisited") done at the British National Hospital for Nervous Disease found that $95.3 \%$ (61 out of 64 ) of conversive disorder patients referred to tertiary-care centers had no neurological explanation after a 6-year follow-up (Crimlisk et al., 1998). Similarly, a study by Mace and Trimble on conversive disorders found that the presenting symptoms were still neurologically unexplained at 10 -year follow-up in $86.0 \%$ (68 out of 79) of their patients (Mace and Trimble, 1996). These two British landmark studies on conversive disorders may not have been considered by the DSM-IV-TR work group.

As the DSM-V publication deadline approaches, it is noteworthy that since the 1994 publication of DSMIV, advances in neuroimaging and other neurological diagnostic techniques have resulted in a decrease in the percentage of localizable neurological lesions misdiagnosed as a conversive disorder. Thus, we predict that the majority of patients diagnosed with conversive disorders will remain in the realm of psychiatry at least for the next decade.

\section{Pseudoneurological symptoms as fitness-enhancing Neolithic fear responses}

There has been surprisingly little discussion of neuroevolutionary etiologies as applied to conversive symptoms. While pseudoneurological symptoms are not part of the pan-mammalian hard-wired fear response sequence (freeze, flight, fight, fright) (Bracha, in press, 2004; Bracha et al., 2004a), we posit below that due to long, nearly continuous warfare during the Neolithic EEA, certain pseudoneurological fear-circuitry responses were selected into the genome of neurally modern humans through what Darwin termed "sexual selection" (also known as mate selection or mate choice). Darwin dedicated 70 pages of his book "Descent of Man, and Selection in Relation to Sex" to human sexual selection. However, it was not until the mid-1990s that experimental psychologists revived Darwin's ideas regarding sexual selection of behavioral traits. Reviews of recent research emphasized the importance of adaptations shaped by Darwin's sexual selection. Miller concluded that "... sex differences are highly diagnostic of sexual selection" (Miller, 2001, p. 226). Similar arguments have been made by Cosmides and Tooby (1999), Campbell (1999), and Morgan (1990).

\section{Neolithic inter-tribal warfare patterns and pseudoneurological conversive symptoms}

It could reasonably be argued that during the Neolithic EEA, any antagonistic encounter with non-kin conspecifics was consistently associated with threats to life. As Perry has noted, dissociative symptoms may have been one of the effective survival responses for some individuals in settled Neolithic communities when under attack by predatory conspecifics (Perry et al., 1995). Similarly, we posit that inheriting nonspecies typical (non-wild type) polymorphic alleles predisposing (firm-wiring), an individual to manifest acute symptoms resembling a neurological injury during extreme fear may have increased the odds of surviving Neolithic inter-group warfare and hence was selected into some genomes. A wide range of such Neolithic evolutionary pressures have been shown to result in a balanced (stable) allele polymorphism (Harvey et al., 1998; Holden and Mace, 1997).

Paleo-anthropological research has documented a specific pattern of prehistoric inter-group warfare in the Neolithic. In contrast to warfare in historical times, Neolithic inter-group warfare almost exclusively involved attacks against non-combatants in unsuspecting settlements by raiding parties of mateless young, post-pubertal males in search of material and especially reproductive resources. Neolithic combat occurred exclusively between young males, with females and children serving as objects of competition. This has been clearly documented by research on prehistoric human remains. It has been estimated that the victors killed $15 \%-50 \%$ of post-pubertal males and most infants and toddlers, and took females and most weaned pre-pubertal individuals captive (Lambert, 1997; Larsen, 1999; LeBlanc and Register, 2003; Maschner and Reedy-Maschner, 1998). These Neolithic patterns of intra-human killing have also been 
confirmed by studies of male lineages through the Y chromosome (Underhill et al., 2001) and of female lineages through mitochondrial DNA (Seielstad et al., 1998).

Fear-induced acute pseudoneurological symptoms were thus probably non-fitness-enhancing for Neolithic post-pubertal males, resulting either in death, severe injury, or, at minimum, a drop in mate availability or in mate choice hierarchy. In contrast, for all reproductive-age women and for weaned pre-pubertal individuals, fear-induced acute pseudoneurological symptoms may have been fitness-enhancing since they increased the likelihood of preserving life and reproduction. Consistent with the above reasoning, conversive symptoms are rare among post-pubertal males (DSM-IV-TR) (Boss, 1997, p. 496). Conversive symptoms are significantly less common among men than women, with reported female-to-male ratios ranging from 2:1 to 10:1 (Boss, 1997). Additionally, epidemiological studies have universally documented that conversive symptoms mostly affect young and healthy individuals under age 20 and rarely occur after age 35 (Boss, 1997).

\section{Subtypes within the sociogenic-conversive spectrum}

\subsection{Acute fear-induced motor deficits}

Conversive motor deficits are typically marked by unilateral pseudo-paralysis (limping) or pseudo-cerebellar symptoms (staggering). We posit that during the Neolithic EEA some healthy individuals who reflexively limped or staggered away rather than engaged in combat were less likely to be attacked by predatory con-specifics during inter-tribal warfare. As Perry et al. have presciently noted, the reverse would be expected if an unsuspecting human settlement was attacked by non-human predators (typically large cats, which prefer to prey on the small, the slow, and the already-injured) (Perry et al., 1995).

\subsection{Sociogenic fear-induced motor (non-epileptic) attacks}

Conversive non-epileptic attacks account for approximately $20 \%$ of all patients discharged from tertiary epilepsy centers (Benbadis, 2001; Krumholz, 1999). Prior to such referrals, patients with acute fearinduced non-epileptic attacks often endure ineffective and costly pharmacological treatment. These patients are often prescribed multiple anti-convulsants due to lack of response. Conversive non-epileptic attacks have also been identified as a significant healthcare cost issue, although exact figures are not available (Goldstein, 2004). Consistent with the neuroevolutionary hypothesis presented here, young women account for approximately $75 \%$ of conversive motor (non-epileptic) attacks (Tojek et al., 2000). This age and sex distribution is similar to fainting induced by bloodletting-related stimuli (Bienvenu and Eaton, 1998).

\subsection{Acute fear-induced epidemic faintness}

There has been little attention paid to the fact that epidemic sociogenic illness is also being reported in developed countries (Brown and Trimble, 2000; Moffatt, 1982; Wessely, 2000). However, a high percentage of the reports on epidemic sociogenic illness are published in languages other than English, making it difficult to summarize all available data. Boss has critically reviewed the 70 English-language reports on epidemic sociogenic illness published between 1973 and 1993 (Boss, 1997). In her comprehensive review, symptoms which we consider in the "faintness-spectrum" (fainting, swooning, dizziness, lightheadedness, pseudo-seizures, unconsciousness) were reported by $84 \%$ of individuals (Boss, 1997). In all published studies of epidemic sociogenic disorders, symptoms were most often reported in healthy individuals under age 20 (Bartholomew and Wessely, 2002; Boss, 1997; Jones et al., 2000; Wessely, 2000). In her review, Boss noted that epidemic sociogenic symptoms frequently occur in indoor settings such as classrooms. Therefore, dehydration, overheating (sunstroke), physical fatigue, and/or prolonged standing are unlikely causative agents of the symptoms. Boss has also called attention to the fact that such epidemic faintness occurs primarily in individuals who are in the line of sight of the index case (Boss, 1997). This is consistent with visual (non-verbal) signaling. There has been little attention paid to the findings of Boss and others that epidemic sociogenic illness most often manifests as epidemic faintness (i.e., faintness in response to the fainting of a peer group member) 
(Boss, 1997; Moffatt, 1982; Van Ommeren et al., 2001).

Epidemic sociogenic syndromes may be ripe for a science-based theoretical conceptualization. In this theoretical article, we posit that during the Neolithic (a period of nearly continuous intertribal predation) seeing a peer drop to the ground (thus appearing severely injured) non-verbally signaled to others in the group that there was a cause for alarm. We posit that a predisposition to faint in response to fainting of a member of one's peer group may have increased the odds of survival. Epidemic faintness in modern clinical settings may be a manifestation of this hard-wired or prepotentiated (firm-wired) neolithic alarm-signaling response, now encoded in some genomes and possibly amplified through assortative mating.

\section{Insights from recent bio-anthropological research}

The high density of populations required for the hypothesis we present in this paper came into existence only in the Neolithic. It may not be immediately obvious that the Neolithic period was of sufficient time depth (i.e., sufficient duration) to allow the spread of balanced polymorphisms. Little-known evolutionary anthropological and allele frequency studies may be instructive in this regard. The Neolithic period lasted approximately 480 generations $(12,000$ years) in those parts of the world that pioneered agriculture and in parts of the world that pioneered pottery. This would have permitted the spread of polymorphic traits with moderate selection coefficients. The best known example of an adaptation, which is specifically of Neolithic time depth (origin) and which entered the human genome as a balanced (stable) polymorphism, is hereditary persistence of intestinal lactase (the ability to digest lactose past the age of four) (Harvey et al., 1998; Holden and Mace, 1997). Cavalli-Sforza et al. have calculated that a high selection coefficient $(3 \%)$ will result in a 100-fold increase in allele frequency in 3800 years. Furthermore, a moderate selection coefficient of $1 \%$ will result in a 100 -fold increase in allele frequency in 11,500 years (e.g., from $0.05 \%$ to $5 \%$ of the population) (Cavalli-Sforza et al., 1994). Thus, we posit that most acute pseudoneurological syndromes are evolved fear-circuits of Neolithic time depth (12,000 years).

Geographical differences are especially instructive. Another example of a balanced polymorphism of Neolithic time depth is the region-specific reduction in the size of human dentition after the development of pottery. Pottery technology was first developed in East Asia in the early Neolithic. Pottery cooking greatly decreased the survival advantage of large teeth in the East Asian culture-bound genomes (European culture-bound genomes still retain tooth size similar to that of the more archaic non-neurally modern humans). A directional selection resulting in a reduction in tooth size, which progressed at $2 \%$ per 1000 years, has been proposed (review by Hill, 2004). Sex differences are also instructive; e.g., reduction in tooth size evolved more rapidly in females than in males. This is attributed to the pioneering role of females in developing both agriculture technologies and pottery technologies and their lower consumption of game meat during the Neolithic (review by Hill, 2004). Our hypothesis that pseudoneurological syndromes are of recent (Neolithic) time depth is also evinced by the observation that the predisposing alleles were not driven to fixation but rather remained species atypical.

\section{Implications for DSM-V and some empirically testable and falsifiable predictions}

The purpose of theory-driven articles is to look at conventional wisdom from a new angle, often from the perspective of a seemingly distant scientific discipline. Hypotheses presented in theory-driven articles are, by definition, conjectural. However, they serve the purpose of generating testable and falsifiable predictions. As Nesse points out, neuroevolutionary hypotheses are not untestable (Nesse, 1999b). Possible implications for the DSM-V research agenda and a few testable and falsifiable predictions are listed below.

\subsection{Predictions for research across culture-bound genomes}

Based on the literature reviewed here, we predict that the highest prevalence of sociogenic pseudoneur- 
ological syndromes would be found in culture-bound genomes whose geographic ancestry is in ecological locations of the globe where agriculture and pottery were pioneered (and thus the Neolithic period lasted the longest). These regions are the Fertile Crescent, North Africa, Anatolia, and parts of South Asia and of East Asia. We predict that pseudo-neurological disorders will demonstrate high genotypic variance as evinced by high h-squared, high phenotypic variance, and lack of universality across cultures.

\subsection{Toward a rapprochement between DSM and the European ICD}

The importance of rapprochement between the forthcoming DSM-V and the ICD taxonomy has been emphasized by Perugi et al. (1998). ICD-10 has re-categorized the conversive disorders and reconceptualized them as more akin to dissociative disorders (Guggenheim, 2000; Kupfer et al., 2002). Our neuroevolutionary perspective also suggests that DSM-V should similarly delete "Conversion Disorders" from the somatization section and reconceptualize them as part of a new "DissociativeConversive Spectrum," with conversive and dissociative syndromes falling along a continuum, as in the ICD-10 and in the forthcoming ICD-11.

\subsection{Conversive (pseudoneurological) disorder may be a more robust construct than dissociation, and thus a better target for biological research}

The nebulous construct of dissociation has been recently widely criticized, primarily for being a heterogeneous syndrome consisting of unrelated etiologies. Research on dissociation over the last three decades has been a challenging enterprise, since neurological phenocopies of dissociation, especially frontal lobe seizures and other hyper-glutamatergic states (endogenous or exogenous), are difficult to rule out. Heuristically, it may be easier to focus early research on the more extreme manifestations of a clinical spectrum. We posit that conversion is a much more robust construct than dissociation. Unlike dissociation, the diagnosis of conversion relies much less on self-report of symptoms and much more on collateral history and clinically observable signs. Clinical research toward the development of the DSM-V and ICD-11 may benefit by shifting some of the focus from dissociative to conversive syndromes, which we posit, lie at the extreme end of the Dissociative-Conversive Spectrum.

\subsection{Implications for the taxonomy of fear-induced faintness in DSM-V}

As we have argued in two recent reviews (Bracha, 2004; Bracha et al., 2005a), blood-injection-injury phobia is a pseudo-neurocardiovascular disorder, which is physiologically puzzling and hemodynamically paradoxical when compared with all other anxiety disorders. We posit that blood-injection-injury fears are better conceptualized as part of a new DSM-V "Dissociative-Conversive Spectrum" because of shared features, which are all in the "faintnessspectrum" (fear-induced fainting, swooning, "medically unexplained dizziness," and lightheadedness). This is consistent with reports in the neurological literature that medically unexplained syncope is highly comorbid with conversive motor (non-epileptic) attacks (Brenner, 1997; Zaidi et al., 1998). More theory-driven research in this inter-disciplinary area between neurology and psychiatry is needed.

\subsection{Some possible implications for the DSM-V terminology}

The current American terminology for the conversive spectrum frequently includes terms that are increasingly perceived as stigmatizing. The British term "acute sociogenic illness," commonly used in Europe, has the advantage of emphasizing the brief nature of these particular pseudoneurological attacks. It was originally coined by Wessely (2000) and may be preferable for this spectrum of conditions, ranging from conversive motor deficits to pseudo-convulsive (non-epileptic) attacks. Other terms such as "acute pseudo-localized disorder" or acute pseudoneurological disorder can also be considered. Sociogenic symptoms in epidemic form have been reported under a variety of names since circa $400 \mathrm{BC}$. The DSM-IV-TR continues to use the original 2400-year-old Herodotian term epidemic "hysteria," which is stigmatizing and should not be retained in DSM-V.

On the other hand, we argue that the prefix "epidemic," used in the DSM-IV-TR (p. 494) should be retained in DSM-V and is preferable to the lay term 
"mass" because it may help minimize association with terms such as "mass injury" and "mass trauma." Furthermore, "epidemic" emphasizes the acute and benign nature of the disorder. The term "epidemic sociogenic attacks" is increasingly used by epileptologists and should also be considered for epidemic sociogenic disorders in DSM-V. An additional advantage of the term "epidemic sociogenic attacks" may be its resemblance to the term "panic attacks" and to "ataque de nervios."

\subsection{Predictions empirically testable in non-human simians}

One testable prediction, based on the Neolithic balanced polymorphism hypothesis, is that sociogenic pseudoneurological symptoms would not be found in extant non-human simians (i.e., that these symptoms are species-specific and limited to neurally modern humans).

\subsection{Predictions for transcriptomic research into the sociogenic (conversive) spectrum}

In addition to anatomically identifying fear-circuits (Bracha et al., in press), it is critical to identify the epigenetic transcriptomic processes involved. One of the major (oligogenic) loci involved in the conversive/dissociative spectrum disorders may carry a developmentally sensitive allele (existing in a balanced polymorphism) in which the expression mechanism is gradually suppressed by pleiotropic androgens, such as dehydroxyepiandrosterone sulfate (DHEA-S). This is likely to manifest as a decrease in gene penetrance following puberty in males. The above prediction is testable and may provide a plausible genetic model for our explanation of the age and sex pattern of sociogenic pseudoneurological disorders. The above hypothesis may thus facilitate a candidategene approach to research into these syndromes.

\subsection{Testable pharmacological treatment approaches}

The possible role of the pleiotropic adreno-cortical androgen DHEA-S is especially intriguing because, unlike testosterone (that decreases during combattraining stress), DHEA-S increases during combattraining stress in males (Charney, 2004; Morgan et al., 2004). DHEA-S is also intriguing from a clinical point of view because, unlike testosterone, it is an over-the-counter compound and may thus be a promising treatment option for sociogenic pseudo-neurological syndromes.

\subsection{Toward stigma reduction in clinical settings}

Acute medically unexplained physical symptoms in young healthy individuals after exposure to war zones are a rapidly growing concern and includes a sub-group with sociogenic etiology (Clauw et al., 2003; Jones and Wessely, 2003). We have argued elsewhere that stigma has been the major self-imposed barrier to early identification and early treatment of medically unexplained physical symptoms, especially in active duty military personnel and veterans (Bracha et al., 2004b, 2005b). We posit that stigma about this spectrum of disorders may be reduced by a new nonpsychodynamic conceptualization and by shifting the emphasis from ontogenetic etiologies to phylogenetic neuroevolutionary etiologies. Diminished stigma may increase acceptability of evidence-based treatments, such as the ones already used for other neuroevolutionarily based fear-circuitry syndromes such as social phobia.

\subsection{Toward a psychiatric taxonomy that is more etiologically based}

The discussion of etiologies has been judiciously minimized in DSM-III, DSM-IV, and DSM-IV-TR. However, the published research agenda for the forthcoming DSM-V has specifically highlighted the need for a more etiologically based classification (Charney et al., 2002; Kupfer et al., 2002). The neuroevolutionary etiological perspective presented in this paper is consistent with, and may serve a useful purpose in, the DSM-V research agenda.

\section{Concluding remarks}

Evolutionary psychiatrists have primarily focused on non-species specific ("basic") fear-circuitry mechanisms, which were wired much earlier than the Neolithic, such as the fear of snakes (which, as we have argued elsewhere, is of Cenozoic time depth 
and thus is a simian-wide fear) (Bracha, in press). Similarly, we have recently articulated a neuroevolutionary hypothesis for other fear-circuitry symptoms which extant humans share with other extant primates-jaw-clenching and tooth-grinding (Bracha et al., 2005b). In contrast, in the present theory-driven article, we attempt to articulate a neuroevolutionary hypothesis for a number of puzzling and difficult-totreat neuropsychiatric syndromes for which an evolutionary hypothesis has not been previously articulated.

It is important to emphasize that:

- We are not proposing newly emerged genomic loci. Rather, we posit that rare allele variants that had little or no survival value throughout most of the Paleolithic EEA (when large African cats were the primary terrestrial predators) did spread widely during the Neolithic EEA when non-kin conspecific predators replaced large cats as the primary cause of premature violent death among young, healthy humans.

- We posit an oligogenic genetic transmission (not a distinctive singular allele) in the etiology of the syndromes addressed in this review. Nevertheless, a candidate gene approach may also warrant exploration.

- Non-protein-coding genome regions responsible for complex modulation of existing genes (e.g., at the transcriptome level), while less well understood at present, are also hypothesized to undergo changes as a result of evolutionary pressures. Single nucleotide polymorphisms in non-protein-coding regions should also be explored as part of future research into the post-genomic etiology of acute sociogenic pseudoneurological syndromes.

\section{In summary}

More theory-driven research on, and a re-conceptualization of, acute pseudoneurological sociogenic symptoms are warranted. In this theoretical article, we endeavor to use creative lumping to obtain a conceptual gain in the understanding of these common, often treatment-resistant symptoms. We present a neuroevolutionary etiological perspective on the acute pseudoneurological symptoms. We argue that some presently hard to treat and perplexing pseudo- neurological symptoms may be traceable to allele variants which were fitness-enhancing during the Neolithic, the latest period of the human EEA. We posit that at the transcriptome level, one of the major oligogenic loci involved may carry a developmentally sensitive allele (in a balanced polymorphism) in which the gene expression mechanism is gradually suppressed in post-pubertal males by pleiotropic androgens, such as DHEA-S. Possible taxonomic implications for rapprochement between the forthcoming DSM-V and the ICD are also discussed.

\section{Acknowledgements}

This material is based upon work supported in part by the Office of Research and Development, Medical Research Service, Department of Veterans Affairs, VA Pacific Islands Health Care System, Spark M. Matsunaga Medical Center. Support was also provided by a National Alliance for Research on Schizophrenia and Depression (NARSAD) Independent Investigator Award, and the VA National Center for Posttraumatic Stress Disorders.

\section{References}

Bartholomew, R.E., Wessely, S., 2002. Protean nature of mass sociogenic illness (from possessed nuns to chemical and biological terrorism fears). The British Journal of Psychiatry 180, 300-306.

Benbadis, S.R., 2001. Provocative techniques should be used for the diagnosis of psychogenic nonepileptic seizures. Archives of Neurology 58, 2063-2065.

Bienvenu, O.J., Eaton, W.W., 1998. The epidemiology of bloodinjection-injury phobia. Psychological Medicine 28, 1129-1136.

Blanchard, R.J., Yudko, E.B., Rodgers, R.J., Blanchard, D.C., 1993. Defense system psychopharmacology: an ethological approach to the pharmacology of fear and anxiety. Behavioural Brain Research 58, 155-165.

Boss, L.P., 1997. Epidemic hysteria: a review of the published literature. Epidemiologic Reviews 19, 233-243.

Bracha, H.S., 2004. Freeze-Flight-Fight-Fright-Faint: adaptationist perspective on the acute stress response spectrum. CNS Spectrums - The International Journal of Neuropsychiatric Medicine 9, 679-685.

Bracha H.S. in press. Neuro-evolutionary factors in the etiology of fear-circuitry-related traits: Current perspectives, falsifiable predictions and the "Time-Depth Principle" Progress in NeuroPsychopharmacology \& Biological Psychiatry. 
Bracha, H.S., Williams, A.E., Ralston, T.C., Bracha, A.S., Matsukawa, J.M., 2004a. Does "Fight or flight" need updating? Psychosomatics 45,5 .

Bracha, H.S., Williams, A.E., Haynes, S.N., Kubany, E.S., Ralston, T.C., Yamashita, J.M., 2004b. The STRS (shortness of breath, tremulousness, racing heart, and sweating): a brief checklist for acute distress, with panic-like sympathetic indicators; development and factor structure. Annals of General Hospital Psychiatry 3,8 .

Bracha, H.S., Bracha, A.S., Williams, A.E., Ralston, T.C., Matsukawa, J.M., 2005a. The human fear-circuitry and fear-induced fainting in health individuals - The paleolithic-threat hypothesis. Clinical Autonomic Research 15, 238-241.

Bracha, H.S., Ralston, T.C., Yamashita, J.M., Williams, A.E., Bracha, A.S., 2005b. The clenching-grinding spectrum and fearcircuitry disorders: clinical insights from the neuroscience-paleoanthropology interface. CNS Spectrums - The International Journal of Neuropsychiatric Medicine 10, 311-318.

Bracha H.S, Garcia-Rill E, Mrak RE, Skinner R. in press. Postmortem locus coeruleus neuron count in three American veterans with probable or possible war-related PTSD. Journal of Neuropsychiatry and Clinical Neuroscience.

Brenner, R.P., 1997. Electroencephalography in syncope. Journal of Clinical Neurophysiology 14, 197-209.

Brown, R.J., Trimble, M.R., 2000. Dissociative psychopathology, non-epileptic seizures, and neurology. Journal of Neurology, Neurosurgery and Psychiatry 69, 285-288.

Buss, D.M., Haselton, M.G., Shackelford, T.K., Bleske, A.L., Wakefield, J.C., 1998. Adaptations, exaptations, and spandrels. American Psychologist 53 (5), 533-548.

Campbell, A., 1999. Staying alive: evolution, culture, and women's intrasexual aggression. Behavioral and Brain Sciences 22, 203-214.

Cavalli-Sforza, L.L., 2000. Genes, Peoples, and Languages, 1 ed. North Point Press, New York.

Cavalli-Sforza, L.L., Menozzi, P., Piazza, A., 1994. The History and Geography of Human Genes. Princeton University Press, Princeton, NJ.

Charney, D.S., 2004. Psychobiological mechanisms of resilience and vulnerability: implications for successful adaptation to extreme stress. American Journal of Psychiatry 161, 195-216.

Charney, D.S., Barlow, D.H., Botteron, K.N., Cohen, J.D., Goldman, D., Gur, R.E., Lin, K.-M., Lopez, J.F., Meador-Woodruff, J.H., Moldin, S.O., Nestler, E.J., Watson, S.J., Zalcman, S.J., 2002. Neuroscience research agenda to guide development of a pathophysiologically based classification system. In: Kupfer, D.J., First, M.B., Regier, D.A. (Eds.), A Research Agenda for DSM-V. American Psychiatric Association, Washington, DC, pp. $31-83$.

Clauw, D.J., Engel, C.C., Aronowitz, R., Jones, E., Kipen, H.M., Kroenke, K., Ratzan, S., Sharpe, M., Wessely, S., 2003. Unexplained symptoms after terrorism and war: an expert consensus statement. Journal of Occupational and Environmental Medicine $45,1040-1048$.

Cook, M., Mineka, S., 1989. Observational conditioning of fear to fear-relevant versus fear-irrelevant stimuli in rhesus monkeys. Journal of Abnormal Psychology 98, 448-459.
Cook, M., Mineka, S., 1990. Selective associations in the observational conditioning of fear in rhesus monkeys. Journal of Experimental Psychology. Animal Behavior Processes 16, 372-389.

Cosmides, L., Tooby, J., 1992. The adapted mind: evolutionary psychology and the generation of culture. Oxford University Press, New York.

Cosmides, L., Tooby, J., 1999. Toward an evolutionary taxonomy of treatable conditions. Journal of Abnormal Psychology 108, $453-464$.

Crimlisk, H.L., Bhatia, K., Cope, H., David, A., Marsden, C.D., Ron, M.A., 1998. Slater revisited: 6 year follow up study of patients with medically unexplained motor symptoms. British Medical Journal 316, 582-586.

Goldstein, L.H., 2004. Assessment of patients with psychogenic non-epileptic seizures. Journal of Neurology, Neurosurgery and Psychiatry 75, 667-668.

Guggenheim, F.G., 2000. Somatoform disorders. In: Sadock, B.J., Sadock, V.A. (Eds.), Comprehensive Textbook of Psychiatry, 7th ed. Lippincott Williams and Wilkins, Philadelphia, pp. $1504-1532$.

Harvey, C.B., Hollox, E.J., Poulter, M., Wang, Y., Rossi, M., Auricchio, S., Iqbal, T.H., Cooper, B.T., Barton, R., Sarner, M., Korpela, R., Swallow, D.M., 1998. Lactase haplotype frequencies in Caucasians: association with the lactase persistence/ non-persistence polymorphism. Annals of Human Genetics 62 (Pt. 3), 215-223.

Hill, M.K., 2004. Dental reduction and diet in the prehistoric Ohio River Valley. Dental Anthropology 17, 34-44.

Holden, C., Mace, R., 1997. Phylogenetic analysis of the evolution of lactose digestion in adults. Human Biology 69, 605-628.

Jones, E., Wessely, S., 2003. "Forward psychiatry" in the military: its origins and effectiveness. Journal of Traumatic Stress 16, $411-419$.

Jones, T.F., Craig, A.S., Hoy, D., Gunter, E.W., Ashley, D.L., Barr, D.B., Brock, J.W., Schaffner, W., 2000. Mass psychogenic illness attributed to toxic exposure at a high school. The New England Journal of Medicine 342, 96-100.

Keeley, L.H., 1996. War Before Civilization: The Myth of the Peaceful Savage. Oxford University Press, New York.

Klein, D.F., 1993. False suffocation alarms, spontaneous panics, and related conditions. Archives of General Psychiatry 50, $306-317$.

Krumholz, A., 1999. Nonepileptic seizures: diagnosis and treatment. Neurology 53, 76-83.

Kupfer, D.J., First, M.B., Regier, D.A., 2002. A Research Agenda for DSM-V. American Psychiatric Association, Washington, DC.

Lambert, P.M., 1997. Patterns of violence in prehistoric hunter-gatherer societies of coastal Southern California. In: Martin, D.L., Frayer, D.W. (Eds.), Troubled Times: Violence and Warfare in the Past. Gordon and Breach Publishers, Australia, pp. 77-109.

Larsen, C.S., 1999. Bioarchaeology: Interpreting Behavior from the Human Skeleton, 1 ed. Cambridge University Press, Cambridge.

LeBlanc, S.A., Register, K.E., 2003. Constant Battles: The Myth of the Peaceful, Noble Savage. St. Martin's Press, New York. 
Mace, C.J., Trimble, M.R., 1996. Ten-year prognosis of conversion disorder. British Journal of Psychiatry 169, 282-288.

Marks, I.M., 1987. Fears, Phobias, and Rituals: Panic, Anxiety, and their Disorders. Oxford University Press, New York.

Marks, I.M., 1988. Blood-injury phobia: a review. American Journal of Psychiatry 145, 1207-1213.

Marks, I.M., Nesse, R.M., 1997. Fear and fitness: an evolutionary analysis of anxiety disorders. In: Baron-Cohen, S. (Ed.), The Maladapted Mind: Classic Readings in Evolutionary Psychopathology. Psychology Press, United Kingdom, pp. 57-72.

Maschner, H.D.G., Reedy-Maschner, K.L., 1998. Raid, retreat, defend (repeat): the archaeology and ethnohistory of warfare on the north Pacific rim. Journal of Anthropological Archaeology $17,19-51$.

Menzies, R.G., Clarke, J.C., 1993. The etiology of fear of heights and its relationship to severity and individual response patterns. Behaviour Research and Therapy 31, 355-365.

Miller, G.F., 2001. The Mating Mind: How Sexual Choice Shaped the Evolution of Human Nature. Anchor Books, New York.

Moffatt, M.E., 1982. Epidemic hysteria in a Montreal train station. Pediatrics 70, 308-310.

Morgan, E., 1990. The Scars of Evolution: What Our Bodies Tell Us About Human Origins. Oxford University Press, Oxford.

Morgan, C.A., Southwick, S., Hazlett, G., Rasmusson, A., Hoyt, G., Zimolo, Z., Charney, D., 2004. Relationships among plasma dehydroepiandrosterone sulfate and cortisol levels, symptoms of dissociation, and objective performance in humans exposed to acute stress. Archives of General Psychiatry 61, 819-825.

Nesse, R.M., 1999a. Proximate and evolutionary studies of anxiety, stress and depression: synergy at the interface. Neuroscience and Biobehavioral Reviews 23, 895-903.

Nesse, R.M., 1999b. Testing evolutionary hypotheses about mental disorders. In: Stearns, S.C. (Ed.), Evolution in Health and Disease. Oxford University Press, Oxford, pp. 260-266.

Niculescu, A., Akiskal, H.S., 2001. Proposed endophenotypes of dysthymia: evolutionary, clinical and pharmacogenomic considerations. Molecular Psychiatry 6, 363-366.

Ohman, A., Mineka, S., 2001. Fears, phobias, and preparedness: toward an evolved module of fear and fear learning. Psychological Review 108, 483-522.

Perry, B.D., Pollard, R., 1998. Homeostasis, stress, trauma, and adaptation: a neurodevelopmental view of childhood trauma. Child and Adolescent Psychiatric Clinics of North America 7, 33.
Perry, B.D., Pollard, R.A., Blakley, T.L., Baker, W.L., Vigilante, D., 1995. Childhood trauma, the neurobiology of adaptation, and "use-dependent" development of the brain: how "states" become "traits". Infant Mental Health Journal 16, 271-291.

Perugi, G., Toni, C., Benedetti, A., Simonetti, B., Simoncini, M., Torti, C., Musetti, L., Akiskal, H.S., 1998. Delineating a putative phobic-anxious temperament in 126 panic-agoraphobic patients: toward a rapprochement of European and US views. Journal of Affective Disorders 47, 11-23.

Poulton, R., Menzies, R.G., Craske, M.G., Langley, J.D., Silva, P.A., 1999. Water trauma and swimming experiences up to age 9 and fear of water at age 18: a longitudinal study. Behaviour Research and Therapy 37, 39-48.

Saygi, S., Katz, A., Marks, D.A., Spencer, S.S., 1992. Frontal lobe partial seizures and psychogenic seizures: comparison of clinical and ictal characteristics. Neurology 42, 1274-1277.

Seielstad, M.T., Minch, E., Cavalli-Sforza, L.L., 1998. Genetic evidence for a higher female migration rate in humans. Nature Genetics 20, 278-280.

Slater, E., 1965. Diagnosis of "hysteria". British Medical Journal 5447, 1395-1399.

Slater, E.T., Glithero, E., 1965. A follow-up of patients diagnosed as suffering from "hysteria". Journal of Psychosomatic Research 9, 9-13.

Stein, D.J., Bouwer, C., 1997. A neuro-evolutionary approach to the anxiety disorders. Journal of Anxiety Disorders 11, 409-429.

Tojek, T.M., Lumley, M., Barkley, G., Mahr, G., Thomas, A., 2000. Stress and other psychosocial characteristics of patients with psychogenic nonepileptic seizures. Psychosomatics 41, 221-228.

Underhill, P.A., Passarino, G., Lin, A.A., Marzuki, S., Oefner, P.J., Cavalli-Sforza, L.L., Chambers, G.K., 2001. Maori origins, Ychromosome haplotypes and implications for human history in the Pacific. Human Mutation 17, 271-280.

Van Ommeren, M., Sharma, B., Komproe, I., Poudyal, B.N., Sharma, G.K., Cardena, E., De Jong, J.T.V.M., 2001. Trauma and loss as determinants of medically unexplained epidemic illness in a Bhutanese refugee camp. Psychological Medicine $31,1259-1267$.

Wessely, S., 2000. Responding to mass psychogenic illness. New England Journal of Medicine 342, 129-130.

Zaidi, A., Clough, P., Scheepers, B., Fitzpatrick, A., 1998. Treatment resistant epilepsy or convulsive syncope? BMJ 317, 869-870. 